\title{
POSSIBILITIES OF THE NUMERICAL SOLUTION OF THE DISLOCATION EVOLUTION EQUATION FOR STOCHASTIC VARIABLES
}

\author{
Ivan Milenin ${ }^{*}$, Lukasz Rauch, Danuta Szeliga, Maciej Pietrzyk \\ AGH University of Science and Technology, al. Mickiewicza 30, 30-059 Krakow, Poland \\ *Corresponding author: imilenin@agh.edu.pl
}

\begin{abstract}
The model describing evolution of dislocation population based on fundamental works of Kocks, Estrin and Mecking (KEM) is a useful tool in modelling of metallic materials processing. In combination with the Sandstrom and Lagneborg approach it can predict changes of the dislocation density accounting for hardening, recovery and recrystallization. Numerical solutions of a one-parameter model (average dislocation density), as well as for two types of dislocations and three types of dislocation are described in the literature. All these solutions were performed for deterministic variables. On the other hand, an advanced modelling of materials requires often an information about distribution of parameters. This is the case when uncertainty of the model has to be evaluated or when an information about distribution of product properties is needed. The latter is crucial when deterioration of local formability is caused by sharp gradients of properties. Thus, the investigation of possibilities of numerical solution for the KEM model with stochastic variables was the main objective of the present work. Evolution equation was written for the distribution function and solution was performed using Monte Carlo method. Analysis of the results with respect to the reliability and computing costs was performed. The conclusions towards selection of the best approach were formulated.
\end{abstract}

Key words: Evolution of dislocations, Stochastic variables, Monte Carlo method

\section{INTRODUCTION}

Modern approaches in advanced modelling of complex materials like multiphase steels often require information about the distribution of the microstructural parameters and resulting mechanical properties. The latter is crucial when sharp gradients of properties cause the deterioration of local formability. Importance of determination of these gradients is discussed in Szeliga at el. (2019). Obtaining the distribution of the factors that influence the gradient of properties is one of the possible approaches to the evaluation of local formability. The three key factors which define the gradient of properties are: carbon distribution in phases, precipitation and evolution of dislocations in ferrite close to the boundary with hard constituents. The current paper is focused on the new approach to modelling evolution of dislocations density, accounting for the stochastic character of this variable.

The model describing evolution of dislocation population based on fundamental works of Kocks, Estrin and Mecking (Mecking \& Kocks, 1981; (Estrin \& Mecking, 1984), known as KEM model is used widely in modelling of materials processing. In combination with the Sandstrom and Lagneborg (1975) approach it is able to predict changes of the dislocation density accounting for hardening, recovery and recrystallization. Numerical solutions for a one-parameter model (average dislocation density) by Ordon et al. (2000), as well as for two types of dislocations by Estrin (1996) and three types of dislocation by Roters et al. (2000) are described in the literature. Among papers, in which dislocation den- 
sity based model was used to describe dynamic recrystallization, the work (Gao et al., 2019) should be mentioned. The Authors of this paper implements their model in the FE program and performed simulations of industrial process of the friction stir welding.

There are also several recent examples of application of this model to cold forming (Schacht et al., 2017) or creep (Yadav et al., 2017). The conventional constitutive models for single crystals, including the kinematics of single-crystal plasticity and dislocation density evolution, are described in the literature, as well (Zhuang et al., 2019). A large number of papers published during the last decade deals with advanced applications of the internal variable method to simulation deformation and microstructure evolution in various alloys, eg. aluminium alloys (Huang et al., 2017; Zamani et al., 2017; Poletti et al., 2019), magnesium alloys (Guo \& Wu, 2018), Mg-Al-Zn alloy (Dini et al., 2018), pure copper (Huang et al., 2009) or lead (He \& Yao, 2019). Pham et al. (2015) used dislocation based model for the quantification of complex strain path response in alloys. Such dislocation features as dislocation forests, walls and channels were distinguished. Review of the publications confirms extensive predictive capabilities of the constitutive modelling based on the evolution of the dislocations populations.

All mentioned approaches solve the constitutive equation for deterministic variables. In the present day, more often the case when uncertainty of the model has to be evaluated as well as an information about distribution of product properties is needed. One of the possible approaches to take into account uncertainty and provide the ability to predict gradients of material properties is the introduction of stochastic variables. Such kind of approach to microstructure evolution modelling was performed by Nastac (2018) and Nastac and Zhang ( 2014). Other applications of this approach include prediction of the stored energy in the material, which can be used in parallel with the micromechanical model to estimate the temperature rise during dynamic plastic deformation (Nieto-Fuentes et al., 2018). Few attempts to apply stochastic solution to describe dislocation motion can be found in the literature but the focus was on the nano-scale analysis. Few decades ago Bako and Groma (1999) proposed computer simulation method based on stochastic integration to investigate the dynamic properties of a system of parallel straight dislocations. Chattopadhyay and
Aifantis (2016) considered spatially inhomogeneous modes, which lead to randomness in the observed deformation structure. Huang et al. (2016) considered probability distribution of dislocation density to describe the dislocation formation in terms of a chain reaction and performed scaling of the hardening exponent to account for the size effect. All these papers, however, consider the effects appearing in the polycrystals materials due to fluctuations of internal stress. The Authors of the present paper focused on the development of the model, which predicts heterogeneity of dislocation density in the microstructure and can be further used to evaluate heterogeneity of the material properties. Thus, the investigation of possibilities of numerical solution for the KEM model with additional recrystallization term for stochastic variables was the main objective of the present work. Selection of the best method and evaluation of computing costs were performed. It is expected that the model will be a usefull tool in modelling various phenomena which depend on dislocation plasticity, eg. phase transformations (Levitas et al., 2013).

In the case of stochastic solution problem of convergence and uniqueness becomes important. To evaluate these features a quantitative comparison of the subsequent stochastic solutions is needed. Comparison of the two solutions given in a form of the distribution function is a challenge. In the present work the method based on the Hellinger distance (Hellinger, 1909) was applied to solve this problem.

\section{BASIC EQUATIONS}

The evolution of the dislocations populations accounting for hardening, recovery and recrystallization in KEM approach is given by:

$$
\dot{\rho}(t)=A_{1} \varepsilon-A_{2} \dot{\varepsilon}-A_{3} \mathfrak{R}(t) \rho(t) \rho\left(t-t_{c r}\right)
$$

where: $\rho$-average dislocation density, $\dot{\varepsilon}$ - strain rate, $t$ - time, $t_{c r}$ - time at which critical dislocation density for dynamic recrystallization $\left(\rho_{c r}\right)$ is reached, $A_{1}$, $A_{2}, A_{3}$ - coefficients, and:

$$
\mathfrak{R}(t)= \begin{cases}0 & \text { for } t \leq t_{c r} \\ 1 & \text { for } t>t_{c r}\end{cases}
$$

As it has been mentioned, numerous examples of the solution of equation (1) for deterministic variables can be found in the literature. Performing the solution for the stochastic variable $\rho(t)$ was the objective of the present work. 


\section{STOCHASTIC MODEL DESCRIPTION}

Solution of equation (1) for deterministic values gives the average values of microstructural parameters. However as it was mentioned above, the distribution of these parameters is needed to predict advanced properties of products. Therefore, an introduction of the dislocation density distribution function into (1) was proposed by Sandstrom and Lagneborg (1975). The quantity

$$
\int_{\rho}^{\rho+\Delta \rho} G[\rho(t), t] d \rho
$$

represents the probability that material has dislocation density in the range between and at the time $t$. It can be interpreted as a volume fraction of the material with given dislocation density.

Thus, the fluctuation in the dislocation density due to storage, recovery and recrystallization is described by the evolution of the volume distributions of dislocations. In the stochastic approach which is proposed in this work the dislocation density at the beginning of the process (time equal 0 ) is presented in a form of a random variable drawn from the given distribution (e.g. a normal one):

$$
G\left(\rho_{0}, 0\right)=\frac{1}{\sqrt{2 \pi \sigma^{2}}} \exp \left(-\frac{\left(\rho_{0}-\rho_{\text {ave }}\right)^{2}}{2 \sigma^{2}}\right)
$$

where: $\mathrm{G}\left(\rho_{0}, 0\right)$ - distribution function of the dislocation density in the time $0, \rho_{0}$ - average dislocation density at the beginning of the process, $\rho_{\text {ave }}-$ average dislocation density in the recrystallized material, which in the present work was assumed as $10^{-4} \mathrm{~m}^{-2}$, $\sigma$-standard deviation.

To determine the $\mathrm{G}(\rho(t), t)$ function, which describes the probability distribution of dislocation density in time the Monte Carlo (MC) method was applied to draw a random variable of the dislocation density. The solution was obtained by solving equation (1) for each of the points selected from the generated distribution (4).

Proposed change in the approach also allows to modify equation (1) to avoid the usage of the artificial concept of critical dislocation density used in equation (1). The new approach allows to present the process in more physical way, including continuous recrystallization process. This improvement is possible by representing the third term in the equation (1) by a formula based on the JMAK (JohnsonMehl-Avrami-Kolmogorov) equation:

$$
\begin{aligned}
& \int_{\rho}^{\rho+\Delta \rho} G[\rho(t), t] d \rho \dot{\rho}(t) \\
& =A_{1} \varepsilon-A_{2} \dot{\varepsilon}-A_{3} \rho^{2}(t)\left\{1-\exp \left[-k\left(t-t_{0}\right)^{n}\right]\right\}
\end{aligned}
$$

where:

$$
\begin{aligned}
& A_{1}=\frac{1}{b l}, \quad l=\frac{A_{10}}{Z^{q}} \\
& A_{2}=A_{20} \exp \left(\frac{Q_{S D}}{R T}\right) \\
& A_{3}=A_{30} \exp \left(\frac{Q_{R X}}{R T}\right)
\end{aligned}
$$

and $\rho$ - dislocation density at a time $t, \mathrm{G}(\rho, t)$ - probability distribution of dislocation density, $Q_{S D}-$ activation energy for self-diffusion, $Q_{R X}-$ activation energy for recrystallization, $b$ - Burgers vector, $l-$ mean free path for dislocations, $Z$ - Zener-Hollomon parameter, $t_{0}$ - time when the last complete recrystallization occurred (each particle had recrystallized at least once), $A_{10}, A_{20}, A_{30}, q, k, n$ - model parameters.

The recrystallization term in the equation (5) is increasing both with time and dislocation density. At the beginning of the deformation process the value of this term is negligible and it grows scientifically with the process progress. Since the resulting change of distribution is unpredictable after the recrystallization term becomes relevant, it is impossible to describe it with a continuous function. Because of this, the whole domain of possible dislocation density values is divided into several intervals and the probability distribution is represented by a set of discrete probabilities, which represents particles having a value from the certain range in the next time step. Within each linear interval the distribution is assumed to be uniform.

Equation (5) is solved using explicit finite difference method and after each time step the set of dislocation density values is achieved. Due to strengthening and recovery represented by the first two terms in equation (5), the dislocation density increases for each Monte Carlo point (or remains constant, when the balance $A_{1}=A_{2} \rho$ is reached). This increment of the dislocation density for each time step is calculated from the explicit schema:

$$
\Delta \rho=\left(A_{1}-A_{2} \rho_{i}\right) \Delta t
$$

where: $\Delta \rho$ - increment of the dislocation density for the current time step $i, \rho_{i}$ - dislocation density gener- 
ated form the probability distributions for the current time step, $\Delta t$ - current time step.

This increase of the dislocation density may force the particle to move to another interval, which in consequence leads to a change of a probability distribution. After the new range is found, the recrystallization term is applied and it determines the probability that recrystallization occurs at the current time step basing on the third term of equation (5):

$p_{\text {recr }}=\frac{\Delta \rho}{\rho_{a v}}=\frac{-A_{3} \rho^{2}(t)\left\{1-\exp \left[-k\left(t-t_{0}\right)^{n}\right]\right\}}{\rho_{a v}}$

The received value indicates the change in the probability of the particle to reach the value in the previously found range. This value is applied by decreasing the probability of particle to stay in the current range without recrystallization and increasing the probability of receiving the initial value after recrystallization occurs. After the change is calculated for each particle, the probability distribution is updated and it is used as an input for the next time step calculations. The flowchart of the standard model run is presented in figure 1 .

\section{NUMERICAL TESTS AND VERIFICATION OF THE MODEL}

Proposed model was implemented and a series of numerical tests was carried out. The tests were performed for coefficients determined for a stochastic model. The values of coefficients for steel were $A_{1}=2.95 \times 10^{14}, A_{2}=17.09, A_{3}=3 \times 10^{-11}$.

The results of simulations for $\varepsilon=1$ are presented in a form of distribution function changes with respect to time. Figure 2 presents the distribution of the dislocation density distribution at different stages of the process. The results are shown in a form of bar charts, which represent the probability of getting a value from the corresponding range. Only the significant part of the domain is shown in the plots.

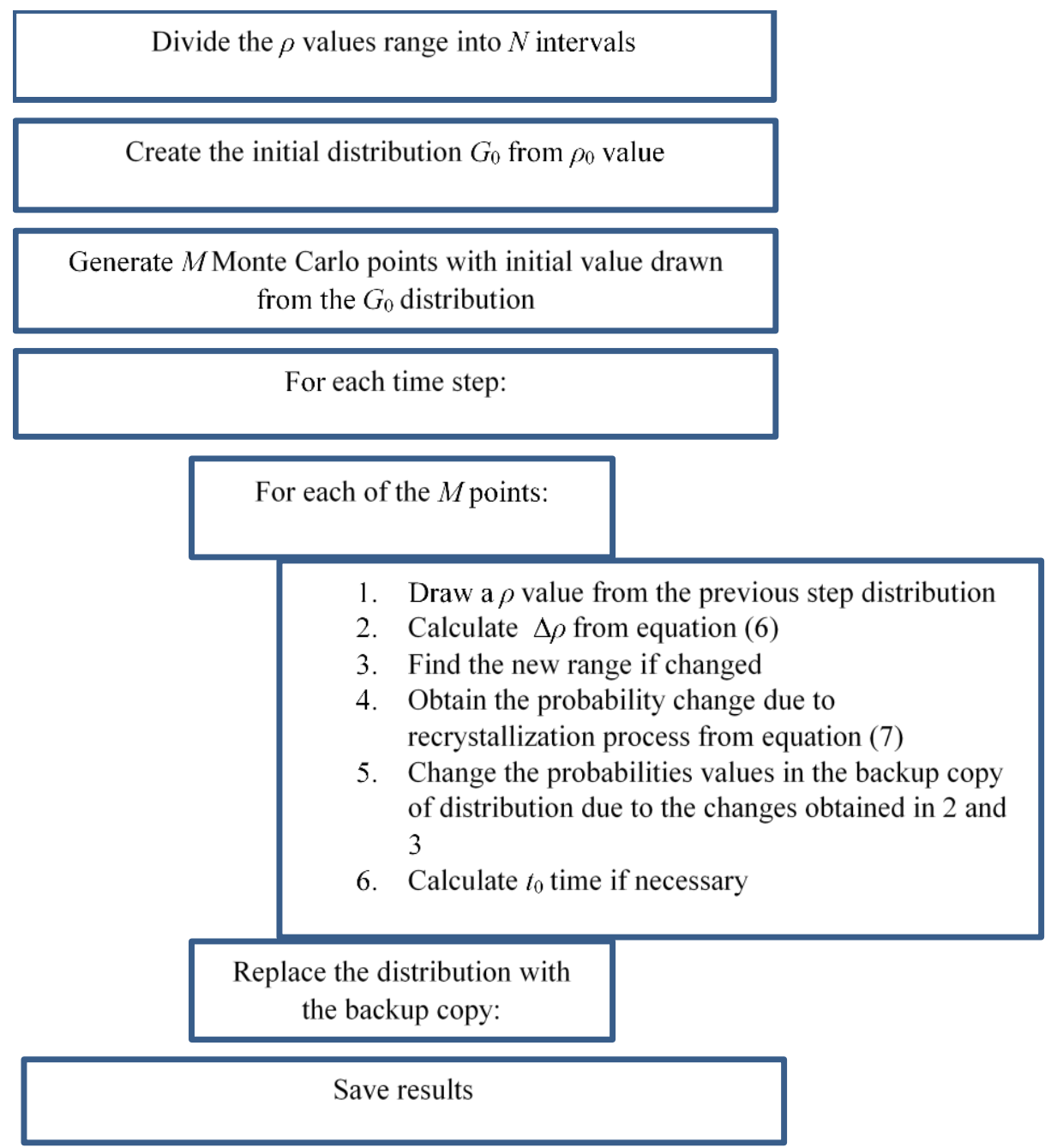

Fig. 1. Flow of the calculations in the model. 


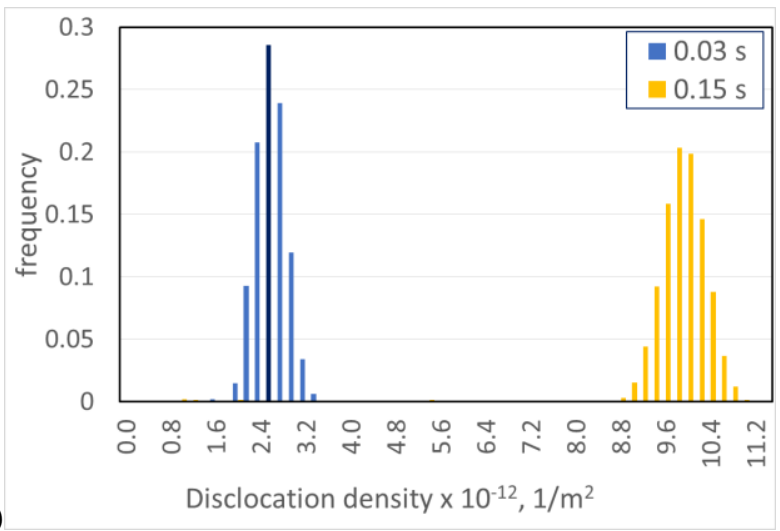

b)
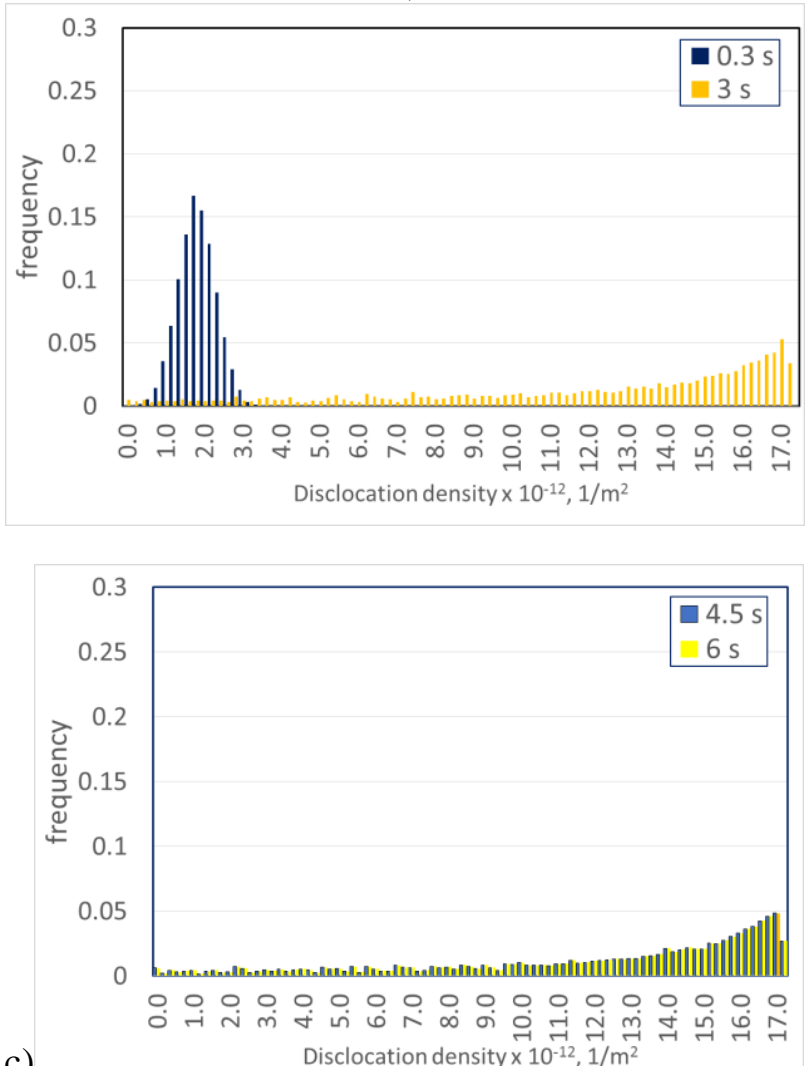

c)

Disclocation density $\times 10^{-12}, 1 / \mathrm{m}^{2}$

Fig. 2. Dislocation density evolution at the different stages of the process (after 0.03 and $0.15 s(a), 0.3$ and $3 s(b), 4.5$ and 6 $s$ (c) for the total strain $\varepsilon=1$.

The received results show the dislocation density evolution in the metallic material in a form of distribution of probability of getting certain dislocation density values by Monte Carlo points. It should be noticed that the character of the distribution changes drastically when the recrystallization process reaches its full rate. The distribution becomes more flat due to the fact that different particles represent parts of the material with different percentage of recrystallized grains.

\section{COMPUTATION TIME AND PREDICTIVE CAPABILITIES CONSIDERATION}

Implementation of the model into the finite element model which simulates thermomechanical processes in the macro scale is the prospective objective of the project. Therefore, the computing costs are one of an important criterion which can possibly prevent this application. Evaluation of the quality of model performance for different input data is essential to prove its ability to be useful in multiscale modelling. The quality can be described by the already mentioned computation time and by the error of the model. As far as computation time can be directly measured while model is running the error of the model can be evaluated by either comparison of received results to the experiment data or by numerical estimation. At the current stage of the model development the numerical estimation was used, since it does not require to perform expensive and time-consuming experiments and gives the necessary information about the quality of the model performance.

The computation time of the model was determined for the coefficients given above. The computation time was measured for different number of Monte Carlo points and the results obtained on a work station with AMD Phenom(tm) II X6 1075T Processor and 8 GB RAM are shown in figure 3.

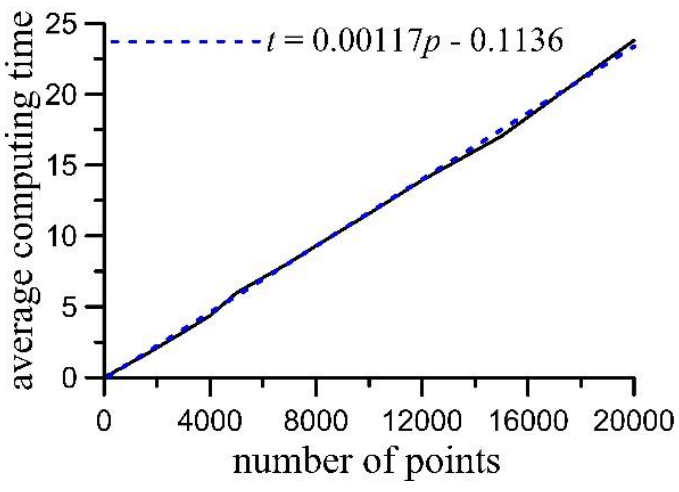

Fig. 3. Computation time of the model as a function of Monte Carlo points number.

From the analysis of the received results it is clearly seen that the computation time increases linearly with the increasing number of the Monte Carlo points. This indicates computational complexity of the problem to be the order of $O(n)$.

Estimation of the error is a more complex problem, since the output of the model is presented in the form of the probability distribution of the dislocation 
density values. The difference between the output probability distribution for two subsequent model runs $i$ and $j$ performed for identical initial data was used as the measure of the error. The difference between probabilities can be calculated in several ways. In the present article, the Hellinger (1909) distance was chosen:

$$
d_{i j}=1-\int_{0}^{\rho_{\max }} \sqrt{G_{i}[\rho(t), t] G_{j}[\rho(t), t]} d \rho
$$

where: $G_{i}[\rho(t), t], G_{j}[\rho(t), t]$, probability distributions for two subsequent model runs $i, j, \rho_{\max }$ - maximum dislocation density.

Since the model includes the numerical solution of the main equation, which leads to representing the distribution in a form of a set of discrete probability values, the Hellinger distance formulation for discrete distribution should be used instead:

$d_{i j}=\frac{1}{\sqrt{2}} \sqrt{\sum_{k=1}^{M}\left(\sqrt{\rho_{i k}}-\sqrt{\rho_{j k}}\right)^{2}}$

where: $\rho_{i k}=\left\{\rho_{i 1}, \rho_{i 2}, \ldots \rho_{i M}\right\}, \rho_{j k}=\left\{\rho_{j 1}, \rho_{j 2}, \ldots \rho_{j M}\right\}-$ two discrete probability distributions for two subsequent model runs, $M$ - number of MC points.

Since the distribution changes with respect to time during the solution process and the whole change is considered as model output, it is necessary to determine the Hellinger distance with respect to time to get the whole picture of the model error change. The determined results for different numbers of Monte Carlo points and for the model coefficients given above are shown in figure 4 .

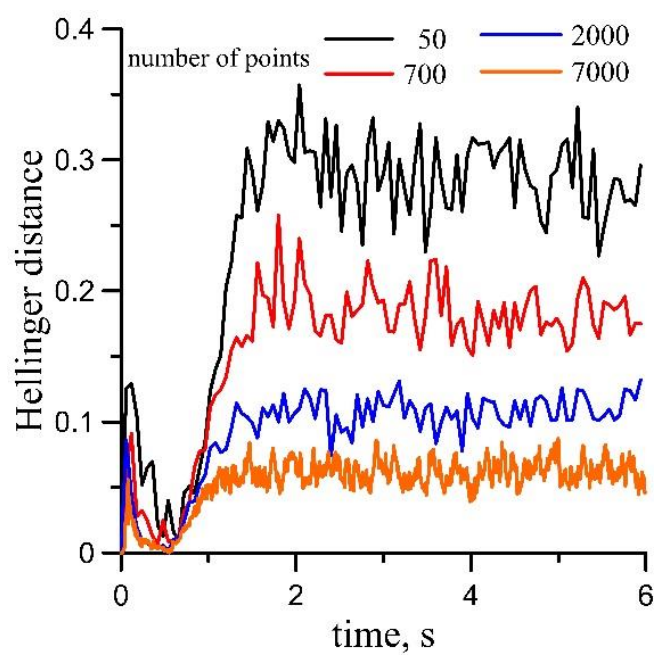

Fig. 4. Average Hellinger distance for different numbers of the Monte Carlo points.
In order to create a simplified measure of the error of the model the average over time Hellinger distance was calculated. This measure describes the overall performance of the model and can be used for further optimization of the number of the Monte Carlo points. The dependence of the average Hellinger distance on the number of points is shown in figure 5 .

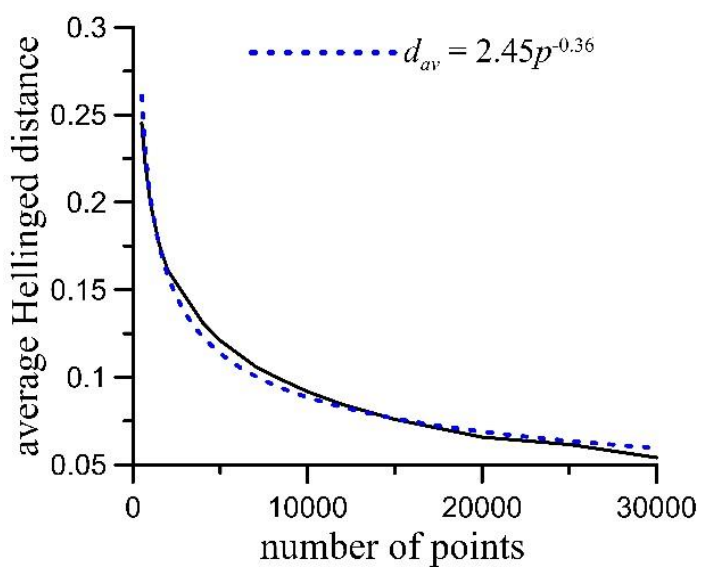

Fig. 5. Average Hellinger distance for different numbers of the Monte Carlo points.

The presented results show that the dependence of Hellinger distance on time is nonlinear and there exists a number of the Monte Carol points, above which the gain in accuracy is too small comparing to the loss in computation time. This point can be considered an optimal number of the Monte Carlo points

\section{OPTIMIZATION OF THE MONTE CARLO POINTS NUMBER}

As it can be concluded from the results received in previous paragraph, there should exist an optimal number of the Monte Carlo points. This value can be found by solving a simple optimization task. In order to formulate the task a goal function should be composed. The quality of model performance was evaluated basing on the two key parameters: computation time and estimated error. In order to be able to compose the goal function, results for both were approximated with mathematical functions. Both curves can be approximated in an accurate enough way with MS Excel trendlines. The relevant equations are presented in figures 3 and 5 respectively. The normalization of the received 
functions is necessary for composition of the goal function. Thus, the goal function can be created as follows:

$\Phi(M)=w_{t} \frac{t(M)}{t_{\max }-t_{\min }}+w_{d} \frac{d(M)}{d_{\max }-d_{\text {min }}}$

where: $M$ - number of the Monte Carlo points, $w_{t}, w_{d}$ - weights of the parameters, $t_{\max }, t_{\min }, d_{\max }, d_{\min }$, borders of the range of the received values of the parameters for computation time and Hellinger distance respectively, $t(M), d(M)$ - approximation function for computation time and Hellinger distance, respectively.

Weights $w_{t}, w_{d}$ define the importance of the parameter for the particular case. The results of the optimization process for different weights are presented in table 1 .

Table 1. Optimal number of the Monte Carlo points for different weights of the parameters.

\begin{tabular}{|c|c|c|}
\hline$w_{1}$ & $w_{2}$ & $M$ \\
\hline 0.5 & 0.5 & 2385 \\
\hline 0.25 & 0.75 & 5282 \\
\hline 0.75 & 0.25 & 1077 \\
\hline 0.1 & 0.9 & 11696 \\
\hline 0.9 & 0.1 & 487 \\
\hline
\end{tabular}

Compatibility of results should be considered satisfactory, taking into account the fact of up to three plastically deformable materials interaction, for which elastic-plastic with hardening models are applied.

\section{CONCLUSIONS}

- The proposed stochastic model can be a viable approach in modelling thermomechanical processing accounting for the recrystallization.

- The usage of Monte Carlo method is a viable approach to solving the main equation of the proposed model.

- The approach gives information about the probability distribution of dislocation density at every time step.

- The solution of the model is reasonably simple and not time-consuming.

- The error of the model was estimated numerically. The Hellinger distance was selected as an error measure. It was shown that there exists a number of the Monte Carol points, above which the gain in accuracy is too small comparing to the loss in computation time.
- Solving a simple optimization task allowed to determine the optimal number of the Monte Carlo points with respect to computation time and estimated error of the numerical solution.

- The proposed model requires an experimental validation and an identification algorithm, which are the main parts of the further research.

\section{ACKNOWLEDGMENTS}

Financial assistance of the NCN in Poland (project no. 2016/23/G/ST5/04059) and DFG in Germany (project no. BL 402/46-1) is acknowledged.

\section{REFERENCES}

Bako, B., Groma, I., 1999, Stochastic O(N) algorithm for dislocation dynamics, Modelling and Simulation in Materials Science and Engineering, 7(2) doi: 10.1088/09650393/7/2/004.

Chattopadhyay, A., Aifantis, E.C., 2016, Stochastically forced dislocation density distribution in plastic deformation, Physical Review E, 94(2), doi: 10.1103/PhysRevE.94. 022139.

Dini, H., Svoboda, A., Andersson, N.-E., Ghassemali, E., 2018, Optimization and validation of a dislocation density based constitutive model for as-cast $\mathrm{Mg}-9 \% \mathrm{Al}-1 \% \mathrm{Zn}$, Materials Science \& Engineering A, 710, 17-26.

Estrin, Y., 1996, Dislocation density related constitutive modelling, in: Unified constitutive laws of plastic deformation, eds, Krausz, A.S., Krausz, K., Academic Press.

Estrin, Y., Mecking, H., 1984, A unified phenomenological description of work hardening and creep based on oneparameter models, Acta Metallurgica, 32, 57-70.

Gao, Z., Feng, J., Wang, Z., Niu, J., Sommitsch, C., 2019, Dislocation density-based modeling of dynamic recrystallized microstructure and process in friction stir spot welding of AA6082, Metals, 9, 672; doi:10.3390/met9060672.

Guo, R., Wu, J., 2018, Dislocation density based model for Al$\mathrm{Cu}-\mathrm{Mg}$ alloy during quenching with considering the quench-induced precipitates, Journal of Alloys and Compounds, 741, 432-441.

He, X., Yao, Y., 2017, A dislocation density based viscoplastic constitutive model for lead free solder under drop impact, International Journal of Solids and Structures, 120, 236244.

Huang, M.X., Rivera-Diaz-del-Castillo, P., Bouaziz, O., Zwaag, S., 2009, Modelling plastic deformation of metals over a wide range of strain rates using irreversible thermodynamics, IOP Conference Series: Materials Science and Engineering, 3, doi: 10.1088/1757-899X/3/1/012006.

Huang, G.R., Huang, J.C., Tsai, W.Y., 2016, Origin of sample size effect: Stochastic dislocation formation in crystalline metals at small scales, Scientific Reports, 6, doi: $10.1038 /$ srep39242

Huang, C., Deng, J., Wang, S., Liu, L.A., 2017, physical-based constitutive model to describe the strain-hardening and dynamic recovery behaviors of 5754 aluminum alloy, Materials Science and Engineering, 699(24), 106-113. 
Hellinger, E., 1909, Neue Begründung der Theorie quadratischer Formen von unendlichvielen Veränderlichen, Journal für die reine und angewandte Mathematik, 136, 210-271.

Levitas, V.I., Roy, A.M., Dean, Preston, L., 2013, Multiple twinning and variant-variant transformations in martensite: Phase-field approach, Physical Review B, 88, 054113.

Mecking, H., Kocks, U.F., 1981, Kinetics of flow and strainhardening, Acta Metallurgica, 29, 1865-1875.

Nastac, L., 2018, 3D Stochastic modelling of microstructure evolution during solidification of alloy 718, Proc. 9th Int. Symp. on Superalloy 718 and Derivatives, Energy, Aerospace and Industrial Applications, Springer, TMS, 379387.

Nastac, L., Zhang, D., 2014, 3D Stochastic Modeling of microstructure evolution during the solidification of dendritic alloys, in: eds, Bernard, D. Buffière, J.Y., Pollock, T., Friis, H., Rollett, P.A., Uchic, M. , Proc. 2nd Int. Congress on 3D Materials Science, Annecy, The Minerals, Metals \& Materials Society.

Nieto-Fuentes, J.C., Rittel, D., Osovski, S., 2018, Dislocation based constitutive model, International Journal of Plasticity, 108, 55-69.

Ordon, J., Kuziak, R., Pietrzyk, M., 2000, History dependent constitutive law for austenitic steels, Proc. Int. Conf. Metal Forming 2000, eds, Pietrzyk, M., Kusiak, J., Majta, J., Hartley, P., Pillinger, I., Publ. A. Balkema, Krakow, 747753.

Pham, M.-S., Iadicola, M., Creuziger, A., Hu, L., Rollett, A.D., 2015, Thermally-activated constitutive model including dislocation interactions, aging and recovery for strain path dependence of solid solution strengthened alloys: Application to AA5754-O, International Journal of Plasticity, 75, 226-243.

Poletti, M.C., Bureau, R., Loidolt, P., Simon, P., Mitsche, S., Spuller, M., 2018, Microstructure Evolution in a 6082 Aluminium Alloy during Thermomechanical Treatment, $\mathrm{Ma}$ terials, 11(8), doi: 10.3390/ma11081319.

Roters, F., Raabe, D., Gottstein, G., 2000, Work hardening in heterogeneous alloys - a microstructural approach based on three internal state variables, Acta Materialia, 48, 41814189.

Sandstrom, R., Lagneborg, R., 1975, A model for hot working occurring by recrystallization, Acta Metallurgica, 23, 387398.

Schacht, K., Motaman, A.H., Prahl, U., Bleck, W., 2017, A unified dislocation density-dependent physical-based constitutive model for cold metal forming, AIP Conference Proceedings, 1896(1), 160020.

Szeliga, D., Chang, Y., Bleck, W., Pietrzyk, M., 2019, Evaluation of using distribution functions for mean field modelling of multiphase steels, Procedia Manufaturing, 27, 7277.

Yadav, S.D., El-Tahawy, M., Kalacska, S., Domankova, M, Yubero, D.C., Poletti, C., 2017, Characterizing dislocation configurations and their evolution during creep of a new $12 \%$ Cr steel, Materials Characterization, 134, 387-397.

Zamani, M., Dini, H., Svoboda, A., Lindgren, L.-E., Seifeddine, S., Andersson, N.E., Jarfors, A.E.W., 2017, A dislocation density based constitutive model for as-cast Al-Si alloys: Effect of temperature and microstructure, International Journal of Mechanical Sciences, 121, 164-170.
Zhuang, Z., Liu, Z., Cui, Y., 2019, Dislocation based crystal plasticity: theory and computation at micron and submicron scale, Elsevier, Academic Press, London, 91-119.

\section{MOŻLIWOŚCI NUMERYCZNEGO ROZWIĄZANIA RÓWNANIE OPISUJĄCEGO EWOLUCJĘ DYSLOKACJI DLA ZMIENNYCH STOCHASTYCZNYCH}

\section{Streszczenie}

Model opisujący ewolucję populacji dyslokacji wykorzystujący fundamentalne prace Kocksa, Estrina i Meckinga (KEM model) jest użytecznym narzędziem w modelowaniu przetwórstwa materiałów metalicznych. W połączeniu z modelem Sandstroma i Lagneborga możliwe jest przewidywanie zmian gęstości dyslokacji uwzględniając zjawiska umocnienia, zdrowienia i rekrystalizacji. Numeryczne rozwiązania dla jednoparametrowego modelu (średniej gęstości dyslokacji), jak i dla dwóch lub trzech rozdajów dyslokacji, jest opisane w literaturze. Te rozwiązania zostały przeprowadzone dla zmiennych deterministycznych. $\mathrm{Z}$ drugiej strony zaawansowane modelowanie materiałów wymaga informacji o rozkładzie parametrów. Ma to miejsce np., kiedy potrzebna jest ocena niepewności wyników lub informacja o funkcji rozkładu własności materiału. To ostatnie jest ważne, kiedy obniżenie lokalnej odporności mateiału na pękanie jest powodowane przez ostre gradienty własności. Stąd celem niniejszej pracy była ocena możliwości numerycznego rozwiązania dla modelu KEM ze zmiennymi losowymi. Równanie ewolucji dyslokacji zapisano dla funkcji rozkładu prawdopodobieństwa i przeprowadzono rozwiązanie wykorzystując metodę Monte Carlo. Przeprowadzono analizę wyników w aspekcie ich dokładności oraz oceniając koszty obliczeń. Sformułowane zostały wnioski sugerujące dobór najlepszych parametrów modelu numerycznego.

Received: October 8, 2019. Received in a revised form: December 27, 2019. Accepted: March 12, 2020. 